\title{
La relación sino-rusa desde una perspectiva histórica
}

DOI: 10.32870/mycp.v8i26.272
José Jesús Bravo Vergara*
$\mathrm{D}$ urante gran parte de su historia común, las relaciones sino-rusas se han caracterizado por el dominio del gigante eslavo, tanto en el aspecto comercial con la concesión de zonas comerciales durante el siglo XIX, así como por su potencia militar y fuerza política, elementos que han influenciado la vida tanto del pueblo como del Estado chino. Ahora, tras 16 años del fin de la Guerra Fría y 14 de la desaparición de la Unión Soviética, China y Rusia se han encontrado en un nuevo contexto internacional con posiciones diferentes a las que tenían cuando Rusia - y luego la Unión Soviética - era una potencia.

El objetivo de este ensayo es establecer las pautas en la política regional - fundamentalmente en Asia Central- de la Federación Rusa y la República Popular de China en este nuevo contexto internacional, así como su interacción frente a la tendencia unilateralista de Estados Unidos.

\section{La invasión mongola}

En comparación con la antiquísima cultura china, el Estado embrionario ruso apenas cuenta con poco más de un milenio de haberse conformado. No obstante,

* Profesor-investigador del Departamento de Estudios Internacionales de la Universidad de Guadalajara. la historia de ambos pueblos encontró la tragedia común en las depredaciones de las hordas mongolas del Gengis Khan y su descendencia, que a partir del siglo XIII, comenzaron con su expansión por los pueblos euroasiáticos.

China fue la primera conquista de Gengis Khan en 1208 cuando cruzó la Gran Muralla con unos trescientos mil jinetes. Para 1213 la zona central de China ya había sido completamente controlada. En 1223 el líder mongol inició una nueva expansión, pero murió en 1227 sin ver terminada su empresa. Su tercer hijo Ogodai tomó el poder y aunque sólo duró dos años, fue con él que en China empezó a reinar la dinastía Yuan. ${ }^{1}$ Posteriormente, Kublai Khan subió al poder y fue proclamado emperador en 1259. Para 1294, el año de su muerte, Kublai Khan ya había derrotado a los restos de la dinastía Sung y controlado casi todo el imperio chino; no obstante, su dinastía terminó en 1368 cuando la dinastía Ming tomó el poder.

Por su parte, en la Rusia de Kiev los mongoles chocaron con las tropas rusas por primera vez en 1223 a orillas del río Kalka y las aniquilaron por completo. Sin embargo, la muerte de Gengis Khan en 1227 hizo que las hordas asiáticas retrocedieran y no volvieran sino hasta después de 13 años, cuando los contingentes de Batú Khan, nieto de Gengis, destrozaron la ciudad provincial de Riazán, donde mataron a la mayoría de sus habitantes. Posteriormen- 
te, otras ciudades rusas también corrieron la misma suerte.

Para 1240 y tras haber destruido Kozelsk, la ciudad de Kiev fue tomada y destruida después de un sitio de varias semanas. Miles de personas fueron exterminadas, hechas prisioneras o vendidas como esclavos. A los que sobrevivieron se les impusieron tributos impagables que se cobraban con gran crueldad. Así comenzó lo que los rusos consideran el gran atraso histórico de más de 200 años respecto a Europa Occidental (Krotkov, 1984: 92 y 97-98).

\section{Una breve sinopsis histórica del desarrollo de la relación política sino-rusa}

Posterior a la etapa de dominio mongol, tanto Rusia como China salieron de su letargo y se deshicieron de sus antiguos conquistadores. En China la dinastía Ming subió al poder en 1368, después de que los descendientes de Kublai Khan fueran víctimas de su propia ineptitud. En Rusia los príncipes de Moscovia comenzaron la llamada reconquista con la derrota mongola en la batalla de Kulikovo en 1380 a manos de Dimitri Ivanovich. A principios del siglo XIV sólo quedaban en Rusia los Kanatos de Kazan, Astracán y Crimea. Los dos primeros fueron tomados por los rusos entre 1552 y 1560 . Por su parte, Crimea fue conquistada por los turcos poco tiempo después de la toma de Constantinopla en 1453 (Grimberg, 1983: 326-327).

La relación oficial entre ambas naciones se empezó a desarrollar cuando el Zar Alejo Mijailovich, hijo de Miguel Romanov, ${ }^{2}$ mandó al Emperador chino su primera embajada en 1656 (Grimberg y Svaström, 1967: 336 y 416-417). No obstante, el desplazamiento de comerciantes de pieles y exploradores rusos a través de Siberia y la Cuenca del Amur, así como la expansión del imperio ruso hacia el centro de Asia, fue contrarrestado por el creciente poder de la dinastía Qing que detuvo el expansionismo de la zarina Sofía, la cual se vio obligada a ceder, por el Tratado de Nerchinsk firmado en 1689, la Cuenca del Amur (Grimberg y Svaström, 1967: 424).

Junto al Tratado de Nerchinsk, ambas partes firmaron otro tratado en 1727, que establecía para rusos y chinos una frontera formal. Asimismo, con el permiso del emperador las caravanas rusas llegaron a la ciudad de Pekín, al tiempo que una misión de la iglesia ortodoxa rusa comenzó a funcionar en dicha ciudad (Fairbank, 1992: 191).

Durante el siglo XIX China comenzó a verse abrumada por la llegada de los europeos a sus costas, ${ }^{3}$ al punto de que la presión británica exigió entenderse en términos de igualdad con el emperador. ${ }^{4}$ Sin embargo, la buena voluntad china contrastó con la corrupción de sus comerciantes y la ambición de los ingleses, quienes en su afán de equilibrar las importaciones de té chino a Gran Bretaña y las exportaciones británicas a la India, impusieron la venta de opio sembrado en esa colonia inglesa al pueblo chino, con lo que desataron en 1839 la denominada guerra del opio, la cual terminaría en 1842 con la firma del Tratado de Nankin y el resultado de una China derrotada, la pérdida de Hong Kong, las puertas abiertas a la venta de opio y la inauguración de la era de los tratados desiguales con otras potencias europeas a las que más tarde se sumarían Japón y Estados Unidos (Zorgbibe, 1997: 142 y 143-144).

En lo que respecta a Rusia, en 1853 el gobierno chino otorgó, por medio del tratado de Aigún, los territorios que están 
a la izquierda del Amur. Posteriormente, en 1860 el imperio chino cedió al imperio zarista los territorios de la Cuenca del Bajo Amur y las tierras al oeste del Usuri por medio del tratado de Pekín (Zorgbibe, 1997: 148). Con ello los llamados tratados desiguales no sólo significaron la pérdida de la soberanía para China, sino también la mutilación de su territorio.

A finales del siglo xIx la intromisión de Japón en los asuntos chinos comenzó a afectar los numerosos intereses rusos en China; ${ }^{5}$ dicha intromisión se acentuó con la derrota de esta última frente a los japoneses en 1895, por lo que un año después Rusia firmó una alianza con el emperador chino en la que se comprometía a proteger a la zona china bajo su influencia de los ataques de un tercero.

Sin embargo, la ocupación de diferentes territorios chinos por parte de los europeos y japoneses alimentó la inquietud rusa y llevó al zar Nicolás II a ocupar Dalian y Port Arthur con el fin de evitar que dichos territorios fueran tomados por los ingleses. Asimismo, obtuvo el derecho de construir el tramo transiberiano entre Manchuria y Port Arthur, así como la expansión de su zona de influencia a la península de Liaodong y los territorios de Xianjiang y Mongolia exterior (Zorbibe, 1997: 148-149 y 150).

Tras las negociaciones japonesas para ocupar Port Arthur y la revuelta fallida de los boxers en 1900, el procónsul ruso en el Extremo Oriente, Alexeiev, firmó un acuerdo secreto con China en el que se colocó a la región de Manchuria bajo la administración del comisario ruso. Con ello, dicha región quedó en calidad de protectorado y preparó el terreno de la confrontación con Japón.

Para febrero de 1904 y tras un ultimátum, Japón declaró la guerra a Rusia cuya flota quedaría destruida casi en su totalidad en 1905 con el célebre hundimiento de la escuadra del Báltico en el estrecho de Tsushima. El resultado fue claro: Rusia tuvo que ceder Liaodong, Port Arthur, los derechos del ferrocarril de Manchuria y la parte meridional de la isla de Sajalín (Zorbibe, 1997: 171-172).

\section{La revolución china y el inicio de la era soviética}

Las humillaciones impuestas por los occidentales enardecieron a las masas de ciudadanos chinos, las que sin respingo decidieron derrocar a su emperador en 1911 y establecer un gobierno republicano en un movimiento dirigido por Sun Yat Sen. Sin embargo, los intereses de poderosos terratenientes locales hicieron estallar un período de guerra conocido como el de "los señores de la guerra" (Roy, 1998: 10-11), al mismo tiempo que el Guomidang o Kuomitang ${ }^{6}$ comenzó su expansión por el país.

Por su parte, tras una serie de derrotas de los ejércitos rusos en el frente oriental europeo entre 1915 y 1917, los bolcheviques se hicieron del poder en Rusia al mando de Vladimir Ilich Ulianov en la llamada Revolución de Octubre y se apresuraron a firmar la paz con Alemania, la cual obtuvieron mediante el Tratado de Brest-Litovsk en marzo de 1918.

Tras una sangrienta guerra civil en la que fue ejecutada la familia real, el régimen soviético se afianzó en el poder y en 1922 se fundó la Unión de República Socialistas Soviéticas (Nóvosti, 1999), con el partido comunista al mando.

Pronto el partido comunista de la Unión Soviética (PCus) trató de expandir su influencia en Europa, pero la derrota frente a las tropas de José Pisuldsky en Polonia en 1921 detuvieron su avanzada 
en la región. Mientras tanto, en Asia el Ejército Rojo avanzó hacia Siberia oriental al ocupar los reductos que japoneses y estadounidenses abandonaron, así como los territorios de Mongolia exterior, donde promovieron en ese año el nacimiento de una república socialista aliada a sus intereses. ${ }^{7}$

En China el pcus entabló sus primeras negociaciones mediante la misión encomendada por Alexander Ioffe en 1922 (Zorgbibe, 1997: 427). De hecho, la Unión Soviética ayudó a la reorganización del Kuomitang, lo que permitió avanzar a las tropas de Chian Kai-Shek desde Cantón hacia el norte de China (Roy, 1998: 10). Sin embargo, la promoción de líderes comunistas al interior de Kuomitang desestabilizó el seno del partido nacionalista y Chian Kai-Shek determinó el asesinato de miles de simpatizantes comunistas, con lo que reforzó su poder personal y redujo algunas pocas células comunistas dentro del territorio chino.

La relación diplomática sino-soviética se rompió tras el descubrimiento de las autoridades de Pekín de una gran cantidad de documentos que demostraron las constantes injerencias de Moscú en los asuntos internos de China, y con ello culminó la primera etapa de la relación sino-soviética a mediados de 1927.

\section{Los conflictos de entre-guerra en el extremo oriente}

Durante la década de los treinta China se vio invadida de nueva cuenta por los japoneses, quienes intentaron expandir a partir del territorio chino, su llamada "Esfera de Coprosperidad Asiática"; no obstante, la realidad era clara: el militarismo japonés expandió su imperio, ocupó Manchuria (Manchukuo en japonés) e instaló un régimen títere en la persona del último emperador de la dinastía manchú, $\mathrm{Pu}$ Yi.

En 1937 un incidente en el Puente de Marco Polo, en Wanping, fue tomado como pretexto por las tropas japonesas para avanzar al interior de China, cuya capital Pekín sería tomada en octubre 1938 (Zorbibe, 1997: 590-592). En diciembre de ese mismo año el gobierno nipón exigió a China, como condición de paz, su división interna y su satelización en el sentido de unión dentro de un pacto antikomitern.

Por su parte, la Unión Soviética tuvo una seria confrontación con Japón en 1939, cuando las unidades del ejército japonés apostadas en el "Manchukuo" atravesaron la frontera e invadieron Mongolia ${ }^{8}$ el 11 de mayo de ese año. No obstante, las tropas soviéticas comandadas por el celebre Georgy Zhukov ${ }^{9}$ - posterior vencedor de los nazis - y las unidades de caballería del ejército mongol comandadas por el general Choybalsan, iniciaron una contraofensiva el 20 de agosto que culminó en un mes después con un saldo de $60 \mathrm{mil}$ bajas para el ejército nipón y más de 650 aviones derribados, e infringieron con ello una significativa derrota a los japoneses y frustraron cualquier tentación posterior de invadir a la URSs desde Siberia.

\section{La relación del PCUS y el PCC antes del nacimiento de la República Popular de China}

Desde el inicio de la invasión japonesa a China en 1931 hasta el final de la II Guerra Mundial, los japoneses desarrollaron una guerra de exterminio contra la población china casi tan parecida a la realizada por los nazis contra la población soviética a partir de 1941. Según algunos datos, la URSS perdió alrededor de 27 millones de

MÉXICO YLACUENCADEL PACÍFICO 155 vol. 8, núm. 26 / septiembre-diciembre de 2005100 
personas mientras que en China murieron cerca de 20 millones.

En el plano político, al inicio de la invasión alemana y el establecimiento de una alianza con Estados Unidos y Gran Bretaña, el Kremlin tuvo que reconocer al líder de Kuomitang, Chiang Kai-shek, ${ }^{10}$ como el jefe de la resistencia unificada china, por temor a perder el apoyo de suministros anglosajones. No obstante, Stalin también hizo hincapié en la premisa de que dicho frente chino incluyera a los comunistas comandados por Mao Tse Tung.

En 1946, tras el fin de la II Guerra Mundial y la derrota y expulsión casi total de los ejércitos japoneses de China, nacionalistas y comunistas rompieron el frente común y reiniciaron las hostilidades armadas en un entorno en el que estadounidenses y soviéticos desarrollaron una intermediación que en ocasiones era bastante confusa.

A mediados de 1946 Chiang Kai-shek instruyó a las tropas japonesas y los ejércitos colaboracionistas chinos, subordinados al Kuomitang, a combatir a los comunistas en las provincias de Henan, Jiangsu, Shanxi, y Shandong. Asimismo, $53 \mathrm{mil}$ marinos estadounidenses ocuparon Pekín y sus alrededores, al tiempo que ayudaron a transportar cerca de medio millón de chinos nacionalistas al norte de China (Anguiano, 2001: 187).

Frente a esta actitud y en espera de sacar provecho, los soviéticos ayudaron a los comunistas chinos a ocupar los enormes depósitos de armas que los japoneses habían abandonado en Manchuria. Estos hechos despejaron la complejidad de la situación y China se convirtió en la primera expresión de la disputa ideológica de posguerra en Asia (Anguiano, 2001: 188-189).

A pesar del apoyo soviético a la persona de Chiang Kai-shek, éste era de carácter táctico, pues no deseaba provocar a Estados Unidos, pero en octubre de 1949, cuando la victoria de los comunistas chinos era inminente, Moscú reconoció a Mao Tse Tung como único representante del pueblo y Estado chino.

\section{La política china de inclinación a un solo lado}

A mediados de 1949, cuando los comunistas aún no controlaban la totalidad de la China continental, Mao Tse Tung definió la postura internacional del nuevo régimen de alineación a la Unión Soviética y el bloque de países que ésta lideraba; ello determinó la enemistad con Estados Unidos y lo que definían como imperialismo capitalista.

Para 1950 el líder norcoreano, Kim II Sung, lanzó un ataque a la parte sur de Corea con el afán de controlar toda la península e instaurar un régimen de tipo comunista. Dicho ataque fue apoyado de forma informal por Stalin al tiempo que recibió el visto bueno de Mao. No obstante, las primeras victorias norcoreanas fueron opacadas casi de inmediato por una potente contraofensiva estadounidense que, bajo la bandera de Naciones Unidas, logró alcanzar las márgenes del río Yalú -en la frontera con Manchuria- pese a las advertencias de China.

Ante el riesgo militar que Pekín percibía en su frontera, el mando estratégico chino optó por utilizar unidades del ejército y la lucha en la península subió de intensidad. No obstante, ante el riesgo que las tropas chinas y la propia China corrían frente al potencial militar convencional y nuclear estadounidense, el gobierno de Mao sostuvo que las tropas chinas en Corea eran voluntarias, aunque nunca nadie dio crédito de ello (Hinton, 1966: 
267). Finalmente, después de tres años de combates en los que incluso intervinieron unidades de la fuerza aérea soviética, ${ }^{11} \mathrm{y}$ ante el peligro de una conflagración aún mayor, la guerra se detuvo por medio de una tregua firmada el 27 de julio de 1953 (Chen, 2000: 401).

El enorme esfuerzo desplegado por Pekín tuvo un efecto encontrado, ya que, por un lado, consideró una victoria moral el haber enfrentado y detenido a la mayor potencia del mundo, mientras que, por el otro, tuvo que asumir las enormes pérdidas humanas, políticas, económicas y sociales, así como el gasto de 10,000 millones de dólares (MDD) en aquel entonces, la imposición de un embargo económico por parte de Estados Unidos y la obstaculización norteamericana para la entrada de la RPC al seno de la ONU (Anguiano, 2001: 202-203). Aunado a lo anterior, el endeudamiento por los préstamos soviéticos complementó el costo general que sufrió China. En suma, todo lo anterior pospuso de forma indefinida la aplicación de programas de avance económico al interior del país.

La relación entre la Unión Soviética y la República Popular China (RPC) comenzó a erosionarse durante la década de los cincuenta, fundamentalmente tras la muerte de Stalin en 1953, debido a que el nuevo líder del Pcus, Nikita Khruschev, desarrolló una política de desestalinización al interior del país, al argumentar que Stalin y su subordinado Beria fueron los culpables de numerosas purgas en el país durante su mandato. Para Pekín el ascenso de Krushev al poder estableció un replanteamiento de las relaciones con la Unión Soviética, debido a que esta situación rompía con el entendimiento que Mao había mantenido con Moscú anteriormente, en el sentido de que entendía y aceptaba su liderazgo.

\section{El rompimiento de la política de inclinación china hacia un solo lado}

Al mismo tiempo que China repensó su relación con la URSS, también intentó completar lo que consideraba su integridad territorial y ello significó utilizar la lucha armada contra los enemigos. Así, entre 1954 y 1955 Pekín intensificó sus reclamos sobre Taiwán, y con el afán de probar la reacción estadounidense y la de su aún aliado soviético, lanzó acciones militares en contra de los nacionalistas, primero mediante el bombardeó con artillería terrestre a varias islas controladas por los nacionalistas cercanas a Fujian y posteriormente con una nueva ofensiva, esta vez, sobre la Isla de Quemoy.

Estados Unidos reaccionó enérgicamente y movilizó la séptima flota para tomar represalias (Roy, 1998: 23), al tiempo que Khruschev advirtió a Washington que cualquier ataque a China sería visto como una agresión a la Unión Soviética: con ello limitó a los norteamericanos a hacer efectivas sus amenazas de represalia contra Pekín.

Sin embargo, ya en privado, los líderes soviéticos criticaron de provocadoras e irresponsables a las acciones militares de los chinos y advirtieron que no apoyarían a Pekín en caso de que una nueva agresión de su parte condujera a la guerra. Con ello también se diluyó la promesa soviética de transferir tecnología nuclear a la RPC (Anguiano, 2001: 221).

Las críticas soviéticas y la reconfiguración de su política exterior que reconocía el derecho de la Yugoslavia de Tito de buscar su propio camino hacia el socialismo, al tiempo que establecía la posibilidad de lograr el comunismo a través de medios democráticos, chocaron con las ideas de desarrollar una lucha total de clases en 
contra de las naciones imperialistas que Mao tanto apoyaba. Ello determinó el final de la inclinación china hacia un lado y en 1959 el rompimiento entre los dos gigantes comunistas se concretó.

\section{La rivalidad sino-soviética y el aislamiento de Pekín}

La desconfianza entre chinos y soviéticos, esencialmente tras la muerte de Stalin y el ascenso de Khruschev, se confirmó en 1959 con la suspensión del programa de colaboración nuclear que Moscú sostenía con Pekín. Las razones se centraron en cuatro puntos esenciales:

1. La persistencia de Pekín de que la guerra contra los imperialistas era inevitable.

2. La Cumbre de Campo David en 1959 en la que Washington y Moscú establecieron la posibilidad de evitar la proliferación nuclear militar.

3. La negativa china de dar acceso al ejército y la marina soviéticos para utilizar sus puertos y su territorio como puntos de patrullaje y observación.

4. La neutralidad de Moscú en la guerra que China e India desarrollaron en 1960. (Anguiano, 2001: 218-221).

Durante la reunión del Partido Comunista Rumano en 1960, Khruschev, quien asistió como invitado, junto con otros representantes de diferentes países comunistas del mundo, criticó la política económica del Gran Salto Adelante desarrollada por Mao, así como su visión global de la política y exclamó que por ello no se le podía confiar a Pekín la tenencia de armas nucleares. Asimismo, comparó a Mao con Stalin por su visión irreal de las cosas y por la idea del culto a la personalidad. A su vez, los representantes chinos acusaron a Khrus- chev de patriarcal y tiránico, así como de traicionar los ideales de Marx, Lenin y Engels (Anguiano, 2001: 222-223).

Ya entrada la década de los sesenta, los acercamientos de Tirana a Pekín por un lado, y de Belgrado a Moscú por el otro, así como la aceptación de la propuesta estadounidense por parte de la Unión Soviética de prohibir la transferencia de tecnología nuclear o la asesoría para desarrollarla, aumentaron la tensión de los dos gigantes comunistas.

Asimismo, mientras que la URss desplegó su diplomacia y compitió en potencial militar con Estados Unidos, China sufría los estragos de la hambruna y la emigración de cientos de miles de chinos, al tiempo que acusó Moscú de promover la migración de los uigures a Kazajstán (Anguiano, 2001: 225).

Ante la impotencia de alejarse y rivalizar con los soviéticos, la dirigencia política china centró su posición en la autosuficiencia y la ortodoxia bolchevique, tal y como lo había hecho durante la guerra civil. Sus esfuerzos variaron entre el logro de desarrollar en 1964 su primer artefacto atómico, hasta la radicalización de aislarse cuando se desarrolló el movimiento denominado Revolución Cultural.

El tema fronterizo entre la URss y China fue otro elemento que incrementó aún más la tensión existente entre los dos países. Por un lado, Mao Tse Tung expresó durante una entrevista otorgada a reporteros japoneses que los tratados desiguales del siglo xIX permitieron que los rusos ocuparan Kamchatka y Vladivostok, y que con su enorme territorio Moscú no precisaba de dichas regiones. Estas palabras fueron interpretadas por la dirigencia soviética como una manifestación de expansión territorial china. 
Para 1969 y ante los problemas internos provocados por la revolución cultural, la dirigencia china decidió utilizar los problemas territoriales con Moscú y lanzó un ataque a la guarnición soviética de la isla de Zhenbao en la frontera del río Ussuri, lo que provocó una respuesta soviética con el despliegue de varias unidades de gran capacidad bélica dentro de sus fronteras y de Mongolia exterior. La escaramuza no tuvo mayores repercusiones militares inmediatas, pero sí influyó para que ambas potencias entablaran negociaciones que sólo fueron solventadas en la década de los noventa.

Posteriormente, con la constante expresión del expansionismo soviético de los años setenta, la RPC comenzó a salir de su letargo internacional, primero al ser aceptada en la onU como el representante del pueblo y Estado chino, y posteriormente al iniciar un acercamiento con Estados Unidos, el cual inició con la diplomacia del Ping Pong y se confirmó con el establecimiento de relaciones diplomáticas en enero de 1979.

\section{El advenimiento de la URSS y la confirmación de China}

Si bien es cierto que la competencia armamentística y tecnológica que desplegó la Unión Soviética con Estados Unidos durante la Guerra Fría produjo una imagen de superpotencia, también es cierto que económicamente la URSS se estaba resquebrajando, y entre los apoyos a los movimientos revolucionarios en diferentes partes del mundo y la preparación de su poderoso ejército el gasto se hacía cada vez más grande y la población civil soviética sufría las consecuencias.

Para 1979 la URss, en su afán de librase de un posible cerco aliado a Estados Uni- dos en Asia Central, y conjurar a la vez la amenaza de un integrismo musulmán que amenazara la estabilidad de las repúblicas soviéticas centroasiáticas, el Kremlin ordenó la invasión de Afganistán.

Esta guerra se prolongó durante diez años y los gastos de guerra fueron incalculables. Varios miles de jóvenes soldados soviéticos murieron, al tiempo que generaron cientos de miles de bajas de soldados y población civil afgana. Políticamente, la URSS perdió gran parte de la simpatía que aún tenía en el Tercer Mundo, pero sobretodo perdió la tranquilidad de la población, la cual el mismo Estado había impuesto por la fuerza.

Por su parte y ante la muerte de Mao Tse Tung, en China ascendió al poder un nuevo grupo dirigido por Deng Xiaoping, un líder preocupado por el aislamiento en el que Mao había dejado al país, pensaba de forma realista sobre cómo explotar el acercamiento con Estados Unidos a través del comercio y su posición en Asia, situación que utilizó para cooperar con Washington e Islamabad en su apoyo a los rebeldes afganos durante la ocupación soviética. A partir de entonces, Pekín incrementó su poder económico y se incorporó al mundo del comercio internacional de forma determinante y exitosa, al tiempo que ganó cierta reputación regional. De esta forma, mientras que la URss perdía poder, China lo comenzaba a ganar.

Finalmente, la Unión Soviética tendría su debacle definitiva después de que Mikhail Gorbachov, un joven líder con afán transformador que pretendía una apertura política y económica para su país y sus aliados en Europa Oriental, ascendiera al poder y fracasara ante la precipitación en la toma de decisiones de carácter político y económico y el poder revanchista de los nacionalismos y las fuerzas centrífugas, 
lo que en su conjunto terminó por hacer estallar la integridad del Estado soviético a finales de 1991.

Por su parte, ante el ejemplo de apertura política de Moscú, en China los estudiantes intentaron presionar al gobierno de Pekín para que implementara políticas similares, pero la dirigencia del Partido Comunista Chino fue contundente al reprimir a los estudiantes en Tiananmen, con lo que confirmó una política económica de apertura gradual y administración estatal.

\section{La nueva relación entre Rusia y China: de la rivalidad a la asociación}

Tras la etapa de rivalidades, amenazas y desconfianzas, la desintegración soviética y la nueva posición de China de potencia emergente, se configuró un nuevo escenario en el que la triangulación estratégica con Washington varió. Ahora, algunos analistas internacionales, esencialmente los realistas y neorrealistas, ${ }^{12}$ han comenzado a ver a China como el sustituto de la URSS en el equilibrio bipolar que existió durante el período de la Guerra Fría.

Por su parte, en los primeros años de la post Guerra Fría, Rusia se vio debilitada al interior por una serie de calamidades que abarcó desde crisis económicas y enfrentamientos étnicos — principalmente en Chechenia - hasta la pérdida del control estatal sobre las principales empresas petroleras y la torpeza política del presidente Boris Yeltsin que lo permitió. Asimismo, al exterior el gigante eslavo se vio cercado en Europa Oriental debido a la ampliación hacia el Este de la OTAN, ampliación promovida por Estados Unidos que apoyó la incorporación de antiguos socios soviéticos en dicha organización militar..$^{13} \mathrm{Al}$ mismo tiempo, Moscú comenzó a entender que su influencia diplomática y política se estaba perdiendo no sólo a escala mundial, sino también regional.

Ante dicha situación, Rusia miró hacia el oriente para acercarse más a China, que a pesar de haber firmado el tratado de "No proliferación de armas nucleares", en 1990 empezó a comprar enormes cantidades de arsenal militar a Moscú a fin de modernizar su aparato militar convencional (Anguiano, 1997: 45). Con ello $\mathrm{y}$ ante el creciente poder de Washington, Pekín y Moscú comenzaron a establecer un acercamiento basado en el comercio, fundamentalmente de armas, tecnología y petróleo.

Para 1995 los dirigentes chinos y rusos afianzaron su acercamiento al pactar un acuerdo fronterizo de disminución de tropas de ambos lados de sus respectivas fronteras, al tiempo que enviaron un comunicado conjunto exhortando a terceros países a no intervenir en asuntos internos, un hecho que se interpretó como una crítica muy clara a los comentarios que funcionarios de Estados Unidos y la Unión Europea hicieron sobre los derechos humanos en China y la guerra de Chechenia en el caso de Rusia (Anguiano, 1997: 163).

En 1996 junto a Tayikistán, Kirguiztán y Kazajstán, China y Rusia firmaron el "Acuerdo de Establecimiento de Confianza en las Áreas Fronterizas" en Shanghai en el cual acordaron reducir sus respectivas tropas fronterizas (Anguiano, 1997: 163); del mismo modo Rusia reconoció la soberanía de China sobre Taiwán y China la soberanía rusa sobre Chechenia. Asimismo, ambos países se opusieron abiertamente a la expansión de la оTAN, a su intervención en Kosovo en 1999 y al hegemonismo estadounidense. 


\section{La repercusión del 9/11 en China y Rusia}

El ascenso de George W. Bush a la presidencia de Estados Unidos configuró una nueva dinámica en la política exterior de Washington. Su preocupación sobre la diversificación de las fuentes suministradoras de hidrocarburos se centró en la región del Caucaso y Asia Central, áreas de importancia vital para Rusia y China. El temor estadounidense se acentuó tras los atentados a las torres gemelas en Nueva York el 11 de septiembre de 2001, debido a que la administración estadounidense señaló a grupos musulmanes radicales protegidos por el gobierno talibán de Afganistán.

Cuando Estados Unidos lanzó sus ataques en contra del régimen talibán en octubre de 2001, recibió un apoyo moral significativo de las grandes potencias. Algunas de ellas visualizaron lo ocurrido en Nueva York como una advertencia de lo que podría pasarles si no se detenía a los responsables de los atentados. Algunos países de Asia Central como Uzbekistán y Kirguizstán vieron los hechos como la oportunidad única de salir de la órbita rusa y de establecer contactos políticos y económicos con Washington, y prestaron su territorio para el emplazamiento de tropas estadounidenses. Incluso, Rusia se sumó a la alianza y proveyó a los estadounidenses y a la Alianza del Norte con apoyo informativo de alta calidad y (Gutiérrez del Cid, 2004: 191), todo ello con el objetivo central de justificar la guerra sin cuartel que ya había sido desplegada contra los rebeldes chechenos. Al mismo tiempo, China apoyó la acción estadounidense, pero recomendó mesura en sus acciones.

Sin embargo, cuando Estados Unidos amplió hacia Irak su cruzada contra el terrorismo, también dejó en claro que su interés real tenía como centro la diversificación de las fuentes de hidrocarburos para satisfacer y asegurar sus necesidades energéticas. Al mismo tiempo, sus acciones comenzaron a emitir el mensaje de delimitación de zonas de influencia y de afectar a la competencia económica que China y Rusia desarrollaron en la región. Todo ello, lejos de impulsar las buenas relaciones con estas potencias, despertó desconfianza y posicionamientos encontrados. Como respuesta, tanto Moscú como Pekín empezaron a desplegar una estrategia de diplomacia tácita en Asia Central y el Caucaso con el fin de mandar un mensaje a Washington.

\section{La asociación estratégica sino- rusa frente al posicionamiento estadounidense en el Caucaso y Asia Central}

Si durante la guerra fría la supuesta amistad eterna basada en la camadería comunista no duró ni diez años, desde el final de dicha etapa histórica y esencialmente en los últimos cinco años, la amistad sinorusa se ha basado en un interés común sustentado en el desarrollo de un mundo multipolar y el rechazo a la unipolaridad expresada por Estados Unidos. ${ }^{14}$

Ambos países han percibido cierta agresividad en las acciones de Washington. Por un lado, China establece que los movimientos de Estados Unidos en Afganistán e Irak están destinados a contener su emergencia por considerarla el rival económico y estratégico más importante en un futuro cercano (Ríos, 2004), además de que es el país con el que tiene el mayor déficit comercial: 200,000 MDD (El Informador, 21 de abril de 2006).

Por su parte, Rusia cuya capacidad productiva en hidrocarburos la ha puesto 
en la mira de las grandes firmas petroleras, entiende que algunos países de su "extranjero próximo"15 son contemplados por Estados Unidos como "zonas de interés vital”, especialmente Azerbaiján (Ríos, 2004). Asimismo, los servicios secretos rusos mencionaron que Washington estaba interesado en que el conflicto checheno perdurara y de ser posible se extendiera a todo el Caucaso, incluso establecieron que el organizador de la toma de rehenes en Beslán en septiembre de 2004, Shamil Basayev, era apoyado a través de instituciones y agencias vinculadas con la CIA (Carrasco: 2004).

Como respuesta, $\mathrm{Ru}$ sia y China desplegaron una diplomacia tácita ${ }^{16}$ que expresó el fin de asumir una postura: no permitir humillaciones y reclamar que como potencias comprometidas con la cooperación y un orden multilateral, sus intereses debían ser tomados en cuenta en la escena internacional.

Un primer paso en el acercamiento sino-ruso fue la firma en 1996, junto a Tayikistán, Kirguiztán y Kazajstán, del acuerdo de la Organización para la Cooperación de Shanghai (OCSh), ${ }^{17}$ el cual prevé la reducción de sus respectivas tropas fronterizas (Anguiano, 1997: 163). Un segundo paso fue el compromiso firmado en 1997 con el fin de reconocer mutuamente su demarcación fronteriza de 4,200 kilómetros cuadrados. No obstante, aún queda en pie el contencioso sobre unas islas del río Amur.

Un tercer punto de acercamiento es el tratado de amistad y cooperación sino-ruso que ambos países firmaron en 2001; en di- cho acuerdo no se contempla la asistencia militar; no obstante, el capítulo referente al factor militar es muy importante debido a los intercambios de información y a que el mercado chino comprende $45 \%$ de las exportaciones de armas de Rusia (Novosti, 15 de agosto de 2005).

En el plano económico la creciente demanda de hidrocarburos por parte de Pekín, prevé la posibilidad de que Rusia contribuya a la construcción de un gasoducto que vaya de Kazajstán a China, al tiempo que le vende grandes cantidades de petróleo. Además, ambos países acordaron en el otoño de 2005 un plan de acciones conjuntas en el terreno económico-comercial con duración de cinco años.

Finalmente, la acción conjunta que ha despertado el mayor despliegue de poder, ${ }^{18}$ es la serie de maniobras militares conjuntas denominada "Misión de Paz 2005" que Moscú y Pekín llevaron a cabo en tierras chinas en agosto de 2005, con la participación de 10,000 efectivos de ambos países (Novosti, 6 de agosto de 2005), maniobras que generaron cierta inquietud a Washington.

Asimismo, en los países de Asia Central la presencia militar de Estados Unidos ha empezado a ser vista como molesta e incluso intromisoria, por ello tras el derrocamiento del presidente de Kirguistán, Askar Akayev, ${ }^{19}$ en un declaración conjunta hecha el 5 de julio de 2005, los países de la OCSh establecieron que las bases estadounidenses en Asia Central debían cerrarse debido a que la campaña de apoyo en su lucha contra el terrorismo en Afganistán ya había terminado y que, por lo tanto, ya 
no era necesaria la presencia de sus tropas en la región. Posteriormente, el propio gobierno de Uzbekistán activó una cláusula de terminación del acuerdo referente a la base K2, en Karshi-Kanabad, el cual obligó a las tropas estadounidenses a retirarse en un plazo de 180 días.

Con lo señalado en el párrafo anterior, Tashkent se congració con China y Rusia, al tiempo que obtuvo cierto apoyo de la población que veía con recelo la injerencia política que Washington comenzaba a tener (Cooley, 2006). ${ }^{20}$ Por su parte, Moscú continúa avanzando en la recuperación de su influencia regional, al tiempo que Pekín ha aparecido en la región como un nuevo imán de conexiones económicas y comerciales en el área.

\section{Conclusión}

Lejos de ser una dicotomía que levita en la rivalidad o la amistad incondicional, la relación histórica entre China y Rusia se centra en una mixtura que abarca conquistas y posiciones encontradas, así como alianzas e intereses comunes. Y si bien es cierto que no hace mucho que ambos países se consideraban enemigos acérrimos dentro de la doctrina comunista, también es cierto que en la actualidad, la reconciliación y la confianza mutua se ha reafirmado.

China, tras el fin de la Guerra Fría, y Rusia, con el ascenso al poder de Vladimir Putin, han desplegado una relación contextual más dinámica entre sí, al tiempo que han incorporado a dicha dinámica a los países del Caucaso y Asia Central con el fin de recuperar y confirmar su influencia en la región y contrarrestar la que Estados Unidos ha tratado de desarrollar.

Sin embargo, para que la relación bilateral se desarrolle favorablemente se debe basar en la confianza mutua: Rusia debe tener en cuenta que China tiene un poder propio, que le gusta tomar sus propias decisiones y que por ello cualquier acción de alcance regional que tome debe ser consultada con su socio. Por su parte, China debe entender que los recursos naturales y militares de Rusia siguen siendo de gran relevancia para su crecimiento económico y que ante el despliegue de políticas unilaterales que Estados Unidos ha lanzado en la región con la finalidad de asegurarse la diversidad de las fuentes de hidrocarburos que hay en el Caucaso y en Asia Central, Moscú se convierte en un poderoso socio estratégico debido a que las acciones estadounidenses también afectan su interés nacional. กำ

\section{Notas}

1 El nombre Yuan no es mongol, sino chino y significa "origen"; ello era una manipulación muy astuta de los mongoles para adular a los chinos. Asimismo, Kublai Khan se convirtió en el primero de su pueblo en preocuparse por el arte y la cultura, aunque jamás dejó de ser un guerrero mongol. Dentro de su gobierno numerosos extranjeros fungieron como consejeros entre los que destacaban persas, armenios e incluso venecianos (Fairbank, 1992: 154-156).

2 Tras los desórdenes provocados por las luchas intestinas por el trono ruso en las que abdicaron "el falso Dimitri” y Vassili Chusky, así como las pretensiones de Segismundo de Polonia y Carlos IX de Suecia, los nacionalistas rusos instauraron a Miguel Feodorovic, de la familia de los Romanov, como el nuevo Zar; partir de entonces y hasta 1916 dicha dinastía reinaría en Rusia (Grimberg y Svaström, 1967: 334-335).

3 Desde el siglo XVII las compañías británicas y holandesas habían iniciado una expansión comercial que alcanzaba las costas chinas, esencialmente en Xiamen; no obstante, en 1759 el emperador ordenó que únicamente el puerto de Cantón fuera abierto al comercio con los europeos (Fairbank, 1992: 240-241).

4 La aceptación de igualdad diplomática con Gran Bretaña destruyó la idea mítica de superioridad del emperador chino frente a los demás gobernantes de la tierra (Fairbank, 1992: 245).

MÉXICO YLACUENCADEL PACÍFICO 163 vol. 8, núm. 26 / septiembre-diciembre de $2005 \perp \mathrm{O}$ 
5 Desde 1891 los rusos habían iniciado la construcción del ferrocarril transiberiano el cual cruzó Manchuria y llegó a Vladivostok (Zorgbibe, 1997: 171-172).

6 Partido Nacionalista Chino.

7 En 1924 los gobiernos de la Unión Soviética y de China llegaron a un acuerdo en el que normalizaban sus relaciones, el régimen de Moscú reconoció que la región de Mongolia Interior era un territorio inalienable del Estado chino, al mismo tiempo que acordaban una administración del ferrocarril de oriente de forma conjunta (Cava, 2001: 273-274).

8 Durante la década de los treinta Mongolia se convirtió, bajo el auspicio soviético, en una república comunista al mando del general Choybalsan.

9 La batalla en la estepa mongola catapultó al General Georgy Zhukov al rango de Mariscal, y durante la operación "Barbarroja”, José Stalin lo nombró como Mariscal de la Unión Soviética. En 1945 Zhukov y sus unidades tomaron Berlín e impusieron la rendición a los Altos Mandos Nazis.

10 Desde 1936 se había establecido un frente unido simbólico en el que Chiang Kai-shek fungía como Jefe de Estado de la República China.

1 Al tiempo que el alto mando militar chino negó la participación del Ejército de Liberación Popular (ELP), los aviones Mig del ejército soviético eran manejados por pilotos de la fuerza aérea soviética, aunque llevaban el distintivo del ELP. Con ello los soviéticos también negaron en su momento la participación de sus unidades en la Guerra de Corea.

12 Los realistas establecen que debido a que Estados Unidos es un poder establecido y China uno emergente, este último representa una amenaza para el primero (Qingguo, 2005: 33).

En ese sentido, Kenneth Waltz asume que el tipo de sistema bipolar otorgó una mayor estabilidad a la estructura mundial; por ello tras la desaparición de la Unión Soviética y el respectivo fin de ese sistema bajo la hegemonía absoluta de Estados Unidos, se sugiere que una nueva lucha por la hegemonía se está presentando con la emergencia de China (Waltz, 2000: 31-32).

Por su parte, en su artículo "One Administration, Two Voices: US China Policy During Bush's First Term", Qingguo cita a John Mearsheimer que, en su afán de establecer la posibilidad de confrontación entre Washington y Pekín, va más lejos al establecer que China podría convertirse en el poder más grande al que Estados Unidos haya enfrentado jamás (Qingguo, 2006: 33).

13 Tras dos ampliaciones de la OTAN, se han incorporado como nuevos socios Estonia, Letonia y Lituania, antiguas repúblicas soviéticas y Polonia, Hungría, República Checa, Eslovaquia, Rumania, Bulgaria, viejos socios soviéticos en el desaparecido Pacto de Varsovia, además de Eslovenia.

14 Con el fin de atenuar sus diferencias con Pekín y lograr un acercamiento, Mikhail Gorbachov ordenó en 1989 que los misiles nucleares que la URSS tenía apuntando a territorio chino fueran retirados (Ríos, 2004).

15 El término "extranjero próximo" es utilizado por los rusos para señalar a las repúblicas independientes que pertenecieron a la Unión Soviética y sobre las cuales pretende seguir incluyendo.

16 La Diplomacia Tácita se refiere a las acciones informales o indirectas a través de comunicados de prensa o acciones como la movilización de ejércitos o la realización conjunta de ejercicios militares dirigidos a emitir una imagen de defensa y asociación con otro país (Pearson y Rochester, 2000: 239 y 241).

17 A dicho acuerdo se sumó posteriormente Uzbekistán, mientras que Mongolia funge como observadora.

18 La visión constructivista de las Relaciones Internacionales establece que los valores identitarios ofrecen la información que un actor desea manifestar a otros sobre sus intereses, sus acciones probables y el rol que tiene en un contexto político específico. Además, explican que el comportamiento de un actor va más allá de los efectos mismos del poder material (Wendt, 1999: 93). Lo anterior indica, entonces, que el poder de un actor no está supeditado a la medición de la fuerza bruta y de las capacidades materiales, sino a lo que se expresa en función de sus identidades y la valoración que otros actores le otorgan.

19 Tras el derrocamiento de Askar Akayev, el nuevo presidente Kurmanbek Bakiyev, presionado por la OSCh, anunció que su gobierno pediría Estados Unidos que retiraran sus tropas del Kirguistán. Posteriormente, Bakiyev anunció que la toma de decisiones en materia de política exterior es independiente de cualquier organización, con lo que la posición de Dushanbe ha quedado indefinida por el momento (Cooley, 2006).

20 Ante la necesidad de tener bases cercanas de abastecimiento para el apoyo de las tropas que intervienen en Afganistán, Estados Unidos 
y Uzbekistán firmaron en marzo de 2002 un acuerdo en el que se estableció una asociación entre los dos países en la guerra contra el terrorismo y los vínculos en los servicios de seguridad. Asimismo, Washington pagaría una renta de varios millones de dólares por el uso del aeropuerto, al tiempo que otorgaría equipo de hardware militar y créditos del Export-Import Bank. Por su parte, Kirguistán también recibió apoyo económico por el uso de la base aérea Ganci, pero en ambos casos el gobierno de Washington pidió el compromiso a Tashkent y Dushanbe de que agilizaran el proceso de democratización y el respeto a los derechos humanos en sus respectivas repúblicas (Cooley, 2006), situación que aceptaron en un principio, pero que comenzó a molestar a las estructuras políticas internas, lo mismo que comenzó a generar desconfianza y recelo de Pekín y Moscú.

\section{Referencias bibliográficas}

Anguiano, E. (2000), "Seguridad regional Asia Pacífico", mimeo, Centro de Estudios del Pacífico, Colegio de México, México, DF.

- (1997), "Seguridad Regional en Asia Pacífico", mimeo, Centro de Estudios del Pacífico, Colegio de México, México, DF, pp. 27-67.

Carrasco, M. (2004), "La responsabilité anglo-saxxone á Beslán", Red Voltaire.

Cava Mesa, M. (2001), "Las alianzas y la paz armada", En J. Carlos Pereira, Histotia de las Relaciones Internacionales, Editorial Ariel, Barcelona.

Chen, J. (2000). China en transición: sociedad, cultura y economía., en T. Fisac y S. Tsang (ed.), Editorial Bellaterra, Barcelona, pp. 393-419.

Cooley, A. (2006), "La política de las bases militares", en Foreing Affairs. Vol. 6. Núm. 1. Enero-marzol..

Fairbank John King (1990). Historia de China: siglos XIX y XX. Editorial Alianza. Madrid

Grimberg, C. (1983), El siglo de Luis XIV, t. 8, Ediciones Daimon, México, DF.

Gutiérrez, T. (2004), "El proyecto regional del laberinto estadounidense", en G. Pérez y A. Gutiérrez, Pensar la guerra: hacia una nueva geopolítica,
Universidad Autónoma Metropolitana y Editorial Quimera, México, DF.

Guzzini, S. (1993), "Structural Power: The Limits of Neorealist Power Analysis", International Organization, vol. 47, núm. 3, pp. 443-478.

Hinton, H. (1966), La China comunista en la política mundial. Unión Tipográfica Editorial Hispanoamericana. Madrid.

BIB = Krotkov, B. (1984), "Años de duras pruebas". Páginas de la historia rusa. SPUTNIK Selecciones de prensa y literatura soviéticas. Mayo.

Pearson, F. y M. Rochester (2000), Relaciones internacionales: situación global en el siglo XXl, McGrawHill, México, DF.

Pereira, Juan Carlos (2001) Historia de las Relaciones Internacionales. Editorial Ariel. Madrid.

Poch de Feliu Rafael (2003). "Entre rusos y chinos". La Vanguardia Digital. Madrid. Octubre.

Qingguo, J. (2006), "One Administration, Two Voices: US-China Policy during Bush's First Term", International Relations of the Asia-Pacific (School of International Studies, Pekin, China), vol. 6.

Ríos, X. (2004), "Rusia y China en el escenario global", Anuario CIP 2004. Roy, D. (1998), China's Foreing Policy, Macmillan Press, Londres.

_ (1998b), "Current Sino-us Relations in Strategic Perspective", Contemporary Southeast Asia (Singapur), vol. 20, núm. 3, pp. 225-240.

Taibo, C. (2004), ¿Hacia dónde nos lleva Estados Unidos? Arrebato imperial y rapiña globales en la política exterior norteamericana. Editorial Liberdúplex.

Waltz, K. (2000), "Structural Realism after Cold War", en International Security, vol. 25, núm.1, pp. 5-41.

__ (1996). "International Politics Is Not Foreign Policy", en Security Studies, vol. 6, núm. 1, pp. 54-57.

Wendt, A. (1999), Social Theory of International Politics. Ideas all the way down? On the Constitution of Power and Interest, Cambridge University Press, Inglaterra.

Zorgbibe, C. (1997), Historia de las Relaciones Internacionales, vol. I, Editorial Alianza Universidad, Madrid.

(1997), Historia de las Relaciones Internacionales, vol. II, Editorial Alianza Universidad, Madrid. 